\title{
MICROHARDNESS TESTING OF RESIN CEMENT VERSUS SONIC BULK FILL RESIN COMPOSITE MATERIAL FOR CEMENTATION OF CAD/CAM COMPOSITE BLOCK WITH DIFFERENT THICKNESS
}

\author{
Ahmed Elzoheiry ${ }^{*}$ Amir Hafez ${ }^{* *}$ and Haitham Amr***
}

\begin{abstract}
Objective: evaluate the microhardness and depth of cure of sonic bulk fill resin composite material for cementation of CAD/CAM composite block with different thicknesses versus the traditionally used dual cured resin cement by assessing microhardness at the top and bottom and calculating bottom/top ratio to determine the depth of cure.

Materials and methods: CAD/CAM resin composite blocks (Grandio) restorative materials were used in the present study. For cementation options, two resin materials were selected: SonicFill 2 bulk fill resin composite (Kerr) and Dual-link universal Resin cement (Bisco). Four sections were prepared from each CAD/CAM blocks thickness of $1 \mathrm{~mm}, 1.5 \mathrm{~mm}, 2 \mathrm{~mm}$ and 3 $\mathrm{mm}$ respectively. Sectioned specimens of each CAD/CAM blocks were then divided according to their thickness into three groups $(n=5)$.Portions of each composite cement were placed on a 1-mm thick transparent glass slide and squeezed to a $100 \mu \mathrm{m}$ film thickness Each specimen was covered with one of the CAD-CAM composite block slabs or left uncovered (control) and then light-cured for $40 \mathrm{sec}$ that was positioned perpendicularly on top and in direct contact with the CAD-CAM slabs or the top glass (control).Micro-hardness was obtained for the top and bottom surface of specimens. The mean microhardness values and hardness ratio \% of the specimens were calculated and tabulated. Microhardness measurements were performed twice; one immediately and after 24 hours. Statistical analysis was performed. Significance of the difference within the same group was evaluated using one way analysis of variance (ANOVA) test, followed by Tukey's post hoc test when ANOVA indicated a significant difference. T test was used to compare between both groups. The level of significance was set at $\mathrm{P}<0.05$.
\end{abstract}

Results: Immediately, in control, a higher mean value was recorded in Sonicfill group, with a statistically significant difference ( $\mathrm{p}=0.011$ ). In $1 \mathrm{~mm}, 1.5 \mathrm{~mm}, 2 \mathrm{~mm}$, a higher mean value was recorded in SonicFill 2 group, with a statistically significant difference $(\mathrm{p}=0.003, \mathrm{p}=0.00, \mathrm{p}=0.00$ respectively). In $3 \mathrm{~mm}$ resin cement recorded a mean value of $0.495 \pm 0.012$.After 24 hours, in

\footnotetext{
* Ass. Professor of Conservative Dentistry, Faculty of Dentistry, Cairo University

** Lecturer of Conservative Dentistry, Faculty of Dentistry, Cairo University

** Lecturer of Fixed Prosthodontic, Faculty of Dentistry, Fayoum University
} 
control, a higher mean value was recorded in resin cement group, with no statistically significant difference ( $\mathrm{p}=0.44)$. In $1 \mathrm{~mm}, 1.5 \mathrm{~mm}$, a higher mean value was recorded in SonicFill 2 group, with no statistically significant difference ( $\mathrm{p}=0.55, \mathrm{p}=0.356$ respectively). In $2 \mathrm{~mm}$, resin cement recorded a significantly higher mean value $(\mathrm{p}=0.00)$. In $3 \mathrm{~mm}$, resin cement recorded a mean value of $0.876 \pm 0.008$

Conclusions: Under the limitation of the current study it could be concluded that bulk fill light cured resin composite as new trend in cementation procedure can be efficiently cured through CAD/CAM composite blocks with thickness not more than $1.5 \mathrm{~mm}$. Indeed, dual curable resin cement remains convenient for cementation of thicker indirect esthetic restoration.

\section{INTRODUCTION}

In the last few years, tooth colored restorative materials had become widely used due to increase patient esthetic demands ${ }^{(1)}$. With the introduction of CAD/CAM technology, posterior restorations can be prepared chairside within only one single appointment. Different categories of materials are now available to the dentist: ceramic blocks, ceramic/glass-polymer blocks (hybrid ceramic) and resin-composite blocks ${ }^{(2,3)}$. The main advantage of $\mathrm{CAD} / \mathrm{CAM}$ resin composite blocks over the conventional resin composite material is that the curing part is not required for $\mathrm{CAD} / \mathrm{CAM}$ resin composite blocks as they are pre-polymerized into ready-to-mill blocks. This controlled and optimized curing may lead to a superiority of resin composite blocks over conventional resin composite material due to more homogeneity, no operator related variables, and mechanical characteristics and no firing required for true one appointment dentistry ${ }^{(2,3)}$. Bearing in mind that providing and retaining good marginal integrity of an indirect restoration fundamentally governs the restoration's durability (4). There are many factors that greatly influence the goal of achieving and maintaining an adequate adhesion. These factors include: A well-established surface treatments at both the tooth and restoration side ${ }^{(5)}$, furthermore, the kind of resin composite cement as well as the curing mode of both adhesive and composite cement. An optimum cure of the cement is indispensable in order to achieve good mechanical properties and avoid cement ditching with its consequences of a higher risk on secondary caries and endodontic/periodontal complications ${ }^{(6)}$.

The degree of conversion (DC) of resin cements has been directly used as a parameter for expecting the clinical performance of restorations. ${ }^{(7-10)}$ There are different forms of resin composite cements; the traditional chemically activated auto-curable composite cements ${ }^{(11,12)}$, most of the currently available cements are dual-curable (chemically and photoactivated, available in a two-component syringe $)^{(13-24)}$ or a new trend category of solely lightcurable (one-component syringe). ${ }^{(25)}$ The absence of chemical initiators in the wholly light-curable composite cements makes their polymerization entirely reliant on the amount of energy of light transmitted through the restorative material (2527). This new trend category of resin composite cements is designated when luting relatively thin and translucent restorations that allow enough light irradiance to activate the photo-initiators present in these materials and initiate the polymerization reaction ${ }^{(25-31)}$.

Recently, there is a growing trend in the clinic to use flowable and regular consistency restorative resin composites as light-curable cements. Their 'on command' setting offers the clinicians more time to properly seat the indirect restoration and to easily remove cement excess, especially in case of difficult accessible subgingival margins. Moreover, they have a stiffer consistency that facilitating excess 
removal, however, some operators use heating to get an enhanced flow during restoration seating. Also Sonic power can enhance the flow properties of the material. Sonic bulk fill composite material combine the high flowing properties and the ability to achieve a curing depth up to $5 \mathrm{~mm}$.Regarding their mechanical properties these restorative resin composite materials are stronger than the less fillerloaded resin cements and hence can be expected to maintain marginal integrity longer, having less liability to wear or wash-out at stress-bearing occlusal margins ${ }^{(25-31)}$.

A positive correlation has been established between hardness and degree of conversion (DC). However, the calculation of the hardness bottom/ top ratio and giving an arbitrary minimum value for this ratio can predict the degree of conversion and depth of cure of resin composite materials as well. ${ }^{(32-36)}$

Therefore, in this study, we aimed to evaluate the microhardness and depth of cure of sonic bulk fill resin composite material used for cementation of CAD/CAM composite block with different thicknesses versus the traditionally used dual cured resin cement by assessing microhardness at the top and bottom and calculating bottom/top ratio to determine the depth of cure.

\section{MATERIALS AND METHODS}

CAD/CAM resin composite blocks (Grandio, voco) restorative materials were used in the present study. For cementation options, two resin materials were selected: SonicFill 2 (Kerr) and Dual-link universal Resin cement (Bisco). All the materials used in this study, their compositions and Manufacturers are presented in Table 1. Four sections were prepared from each CAD/CAM blocks using a slow-speed diamond wafering blade (Ernst Leitz GmbH, Wetzlar, Germany) with a thickness of $1 \mathrm{~mm}, 1.5 \mathrm{~mm}, 2 \mathrm{~mm}$ and $3 \mathrm{~mm}$ respectively. Sectioned specimens of each CAD/CAM blocks were then divided according to their thickness into three groups $(\mathrm{n}=5)$.

Portions of each composite cement were placed on a 1-mm thick transparent glass slide and squeezed to a $100 \mu \mathrm{m}$ film thickness using a $100-\mu$ m-thick cover glass slides positioned on top. The luting space thickness was standardized by maintaining two other $100 \mu \mathrm{m}$-thick cover glasses aside the cement. Each specimen was covered with one of the CAD-CAM composite block slabs or left uncovered (control) and then light-cured for $40 \mathrm{sec}$ using BlueLex LED LD-105curing unit (Monitex, Taiwan) with light intensity $1000 \mathrm{mw} / \mathrm{cm} 2$ ) . Light curing unit was positioned perpendicularly on top and in direct contact with the CAD-CAM slabs or the top glass (control).

Prior to the Micro-hardness measurement, the previous specimens were longitudinally polished using a sequence of 800-1200-4000 grit silicon carbide paper and alumina polishing paste $(1 \mu \mathrm{m})$. Surface Micro-hardness of the specimens was determined using Digital Display Vickers Microhardness Tester (Model HVS-50, Laizhou Huayin Testing Instrument Co., Ltd. China) with a Vickers diamond indenter and a 20X objective lens. A load of $100 \mathrm{~g}$ was applied to the surface of the specimens for 20 seconds. Three indentations, which were equally placed over a circle and not closer than 0.5 $\mathrm{mm}$ to the adjacent indentations, were made on the surface of each specimen. The diagonals length of the indentations were measured by built in scaled microscope and Vickers values were converted into micro-hardness values.

\section{Micro-hardness calculation}

Micro-hardness was obtained using the following equation: $\mathrm{HV}=1.854 \mathrm{P} / \mathrm{d} 2$ where, $\mathrm{HV}$ is Vickers hardness in $\mathrm{Kgf} / \mathrm{mm} 2$, P is the load in $\mathrm{Kgf}$ and $\mathrm{d}$ is the length of the diagonals in mm. Five VK readings were recorded for each sample surface (top and bottom). For a given specimen, the five hardness 
TABLE (1) Materials used in the study

\begin{tabular}{|c|c|c|c|}
\hline Material & Type & Manufacturer & Composition \\
\hline Grandio & $\begin{array}{l}\text { Nano- Hybrid } \\
\text { composite CAD / } \\
\text { CAM block }\end{array}$ & $\begin{array}{l}\text { Voco GmbH, } \\
\text { Germany, Cuxhaven }\end{array}$ & $86 \% \mathrm{w} / \mathrm{w}$ inorganic fillers in a polymer matrix. \\
\hline SonicFill2 & $\begin{array}{l}\text { bulk fill light- } \\
\text { cured, low-shrink, } \\
\text { resin-based, dental } \\
\text { restorative }\end{array}$ & $\begin{array}{l}\text { Kerr Corporation } \\
1717 \text { West Collins } \\
\text { Avenue, Orange, CA } \\
92867\end{array}$ & $\begin{array}{l}\text { 60-100\%glass, oxide, chemicals } 5-10 \% \text { Silicon dioxide, } \\
1-5 \% \quad \text { (1-methylethylidene) bis (4,1-phenyleneoxy- } \\
2,1 \text {-ethanediyloxy-2,1-ethanediyl) } \quad \text { bismethacrylate, } \\
1-5 \% \quad(1-\text {-methylethylidene) bis [4,1-phenyleneoxy } \\
\text { (2-hydroxy-3,1-propanediyl)] bismethacrylate, 1-5\% } \\
2,2 \text { '-ethylenedioxydiethyl dimethacrylate }\end{array}$ \\
\hline $\begin{array}{l}\text { D u o - L i n } \mathrm{k} \\
\text { universal }\end{array}$ & $\begin{array}{l}\text { Dual cured resin } \\
\text { lutting cement }\end{array}$ & $\begin{array}{l}\text { Bisco, Inc. } \\
\text { Schaumburg USA }\end{array}$ & $\begin{array}{l}\text { Base: } 10-20 \% \text { Ytterbium Fluoride, } 10-30 \% \text { Bisphenol A } \\
\text { Diglycidylmethacrylate,10-30\% Urethane Dimethacrylate, } \\
\text { 1-5\%Ytterbium Oxide-Silica, 1-5\% Tetrahydrofurfuryl } \\
\text { Methacrylate,1-5\% Trimethylolpropane Trimethacrylate, } \\
\text { >2 3-(Trimethoxysilyl)propyl-2-Methyl-2-Propenoic Acid } \\
\text { Catalyst: 10-30\%Bisphenol A Diglycidylmethacrylate, } \\
\text { Dibenzoyl Peroxide, >1 technically pure }\end{array}$ \\
\hline
\end{tabular}

values for each surface were averaged and reported as a single value. The mean microhardness values and hardness ratio $\%$ of the specimens were calculated and tabulated using the formula: Hardness ratio $\%=$ VK of bottom surface $/$ VK of top surface $X$ 100. Microhardness measurements were performed twice; one immediately and after 24 hours.

\section{STATISTICAL ANALYSIS}

Statistical analysis was then performed using a commercially available software program (SPSS 19; SPSS, Chicago, IL, USA). As data were parametric, significance of the difference within the same group was evaluated using one way analysis of variance (ANOVA) test, followed by Tukey's post hoc test when ANOVA indicated a significant difference. $\mathrm{T}$ test was used to compare between both groups. Mean immediate and 24 hours resin cement values were compared using paired $t$ test. The interaction of the group and depth variables was evaluated using 2 ways ANOVA. The level of significance was set at $\mathrm{P}<0.05$.

\section{RESULTS}

\section{A-Comparison between both groups}

Immediately, in control, a higher mean value was recorded in Sonicfill group, with a statistically significant difference $(\mathrm{p}=0.011)$. In $1 \mathrm{~mm}, 1.5 \mathrm{~mm}$, $2 \mathrm{~mm}$, a higher mean value was recorded in SonicFill 2 group, with a statistically significant difference ( $\mathrm{p}=0.003, \mathrm{p}=0.00, \mathrm{p}=0.00$ respectively). In $3 \mathrm{~mm}$ resin cement recorded a mean value of $0.495 \pm 0.012$ (Table 2, Fig.1)

After 24 hours, in control, a higher mean value was recorded in resin cement group, with no statistically significant difference $(\mathrm{p}=0.44)$. In 1 $\mathrm{mm}, 1.5 \mathrm{~mm}$, a higher mean value was recorded in SonicFill 2 group, with no statistically significant difference ( $p=0.55, p=0.356$ respectively). In $2 \mathrm{~mm}$, resin cement recorded a significantly higher mean value ( $\mathrm{p}=0.00$ ). In $3 \mathrm{~mm}$, resin cement recorded a mean value of $0.876 \pm 0.008$ (Table 3, Fig.1) 


\section{B- Comparison of different depths within the same group}

In resin cement, the highest mean value was recorded in control, while the lowest values were recorded in $2,3 \mathrm{~mm}$, with a statistically significant difference $(p=0.00)$. Tukey' s post hoc test revealed no significant different between 2 and $3 \mathrm{~mm}$ (Table4, Fig.1)

In resin cement 24 hours, the highest mean value was recorded in $1 \mathrm{~mm}$, while the lowest values were recorded in $1.5 \mathrm{~mm}, 2,3 \mathrm{~mm}$, with a statistically significant difference $(\mathrm{p}=0.00)$. Tukey' $\mathrm{s}$ post hoc test revealed no significant different between 1.5, 2 and 3mm. (Table4, Fig.1)
In SonicFill 2, the highest mean value was recorded in $1 \mathrm{~mm}$, while the lowest values were recorded in $2 \mathrm{~mm}$, with a statistically significant difference $(\mathrm{p}=0.00)$. Tukey' s post hoc test revealed no significant different between control and $1.5 \mathrm{~mm}$ (Table4, Fig.1)

\section{C- Comparison between resin cement groups (immediately and after 24 hours)}

Comparing mean immediate and 24 hours resin cement values, revealed a higher mean value after $24 \mathrm{hrs}$ in control and all depths. This difference was not statistically significant in control $(\mathrm{p}=0.62)$, but was extremely significant at 1. 1.5, 2 and $3 \mathrm{~mm}$ $(\mathrm{p}=0.00)$, (Table 5, Fig.1)

TABLE (2) Comparison between mean immediate values of both groups (Independent $t$ test)

\begin{tabular}{|c|c|c|c|c|c|c|}
\hline \multirow[t]{2}{*}{ Material } & & \multicolumn{5}{|c|}{ (B/T ratio) } \\
\hline & & control & $1 \mathrm{~mm}$ & $1.5 \mathrm{~mm}$ & $2 \mathrm{~mm}$ & $3 \mathrm{~mm}$ \\
\hline \multirow[t]{2}{*}{ Resin cement } & Mean & .968 & .895 & 649 & .485 & .495 \\
\hline & SD & 0.1 & .019 & .016 & .012 & .012 \\
\hline \multirow[t]{2}{*}{ SonicFill 2} & Mean & .988 & 1.011 & .886 & .559 & - \\
\hline & SD & .008 & .046 & .021 & .019 & - \\
\hline \multicolumn{2}{|c|}{$\mathrm{t}$} & -3.36 & -5.21 & -20.35 & -7.37 & - \\
\hline \multicolumn{2}{|c|}{$\mathrm{P}$} & 0.011 & 0.003 & $0.00 *$ & $0.00 *$ & - \\
\hline
\end{tabular}

Significance level $\mathrm{P}<0.05$, * significant

TABLE (3) Comparison between mean values of both groups after 24 hours (Independent $t$ test)

\begin{tabular}{|c|c|c|c|c|c|c|}
\hline & & \multicolumn{5}{|c|}{ (B/T ratio) after 24 hours } \\
\hline & & control & $1 \mathrm{~mm}$ & $1.5 \mathrm{~mm}$ & $2 \mathrm{~mm}$ & $3 \mathrm{~mm}$ \\
\hline \multirow[t]{2}{*}{ Resin cement } & Mean & .991 & .998 & .876 & .876 & .876 \\
\hline & SD & .002 & .008 & .009 & .007 & .008 \\
\hline \multirow[t]{2}{*}{ SonicFill 2} & Mean & .988 & 1.011 & .886 & .559 & -- \\
\hline & SD & .008 & .046 & .021 & .019 & --- \\
\hline \multicolumn{2}{|c|}{$\mathrm{t}$} & 0.813 & 0.623 & 0.98 & 35.01 & --- \\
\hline \multicolumn{2}{|c|}{$\mathrm{P}$} & $0.44 \mathrm{~ns}$ & $0.55 \mathrm{~ns}$ & $0.356 \mathrm{~ns}$ & $0.00 *$ & --- \\
\hline
\end{tabular}

Significance level $P<0.05$, * significant, $n s=$ non-significant 
TABLE (4) Comparison of mean values within the same group (ANOVA test)

\begin{tabular}{|c|c|c|c|c|c|c|c|c|c|c|}
\hline & & \multirow{2}{*}{ Mean } & \multirow{2}{*}{ Std. Dev } & \multirow{2}{*}{ Std. Error } & \multicolumn{2}{|c|}{ 95\% Confidence Interval for Mean } & \multirow{2}{*}{ Min } & \multirow{2}{*}{ Max } & \multirow{2}{*}{$\mathrm{F}$} & \multirow{2}{*}{$\mathrm{P}$} \\
\hline & & & & & Lower Bound & Upper Bound & & & & \\
\hline \multirow{5}{*}{ 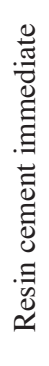 } & Control & $.968^{\mathrm{a}}$ & .010 & .005 & .955 & .981 & .956 & .978 & & \\
\hline & $1 \mathrm{~mm}$ & $.895^{\mathrm{b}}$ & .019 & .009 & .871 & .919 & .874 & .923 & 1241.528 & $.000 *$ \\
\hline & $1.5 \mathrm{~mm}$ & $.649^{c}$ & .016 & .007 & .630 & 669 & .629 & 669 & & \\
\hline & $2 \mathrm{~mm}$ & $.485^{\mathrm{d}}$ & .012 & .005 & .470 & .500 & .470 & .495 & & \\
\hline & $3 \mathrm{~mm}$ & $.495^{\mathrm{d}}$ & .011 & .005 & .481 & .510 & .483 & .508 & & \\
\hline \multirow{5}{*}{ 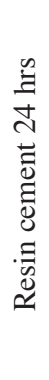 } & Control & $.991^{\mathrm{b}}$ & .002 & .001 & .991 & .996 & .992 & .997 & \multirow{5}{*}{429.63} & \multirow{5}{*}{$.000^{*}$} \\
\hline & $1 \mathrm{~mm}$ & $.998^{\mathrm{a}}$ & .008 & .003 & .984 & 1.003 & .980 & .998 & & \\
\hline & $1.5 \mathrm{~mm}$ & $.876^{\mathrm{c}}$ & .009 & .004 & .864 & .887 & .860 & .883 & & \\
\hline & $2 \mathrm{~mm}$ & $.876^{\mathrm{c}}$ & .007 & .003 & .861 & .879 & .861 & .877 & & \\
\hline & $3 \mathrm{~mm}$ & $.876^{\mathrm{c}}$ & .008 & .003 & .863 & .882 & .860 & .880 & & \\
\hline \multirow{5}{*}{ 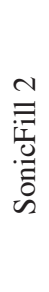 } & Control & $.988^{\mathrm{a}, \mathrm{b}}$ & .008 & .003 & .978 & .997 & .978 & .998 & & \\
\hline & $1 \mathrm{~mm}$ & $1.011^{\mathrm{a}}$ & .046 & .021 & .954 & 1.069 & .983 & 1.093 & 293.601 & $.000^{*}$ \\
\hline & $1.5 \mathrm{~mm}$ & $.886^{\mathrm{b}}$ & .021 & .009 & .860 & .911 & .870 & .917 & & \\
\hline & $2 \mathrm{~mm}$ & $.559^{\mathrm{c}}$ & .019 & .008 & .535 & .582 & .535 & .584 & & \\
\hline & $3 \mathrm{~mm}$ & . & & & & & & & & \\
\hline
\end{tabular}

\section{Significance level $P<0.05$, * significant}

Tukey's post hoc test: Within the same comparison, means sharing the same superscript letter are not significantly different

TABLE (5) Comparison between mean immediate and 24 hours resin cement values values of both groups (paired t test)

\begin{tabular}{|c|c|c|c|c|c|c|}
\hline \multirow[t]{2}{*}{ Material } & & \multicolumn{5}{|c|}{ (B/T ratio) } \\
\hline & & control & $1 \mathrm{~mm}$ & $1.5 \mathrm{~mm}$ & $2 \mathrm{~mm}$ & $3 \mathrm{~mm}$ \\
\hline \multirow{2}{*}{$\begin{array}{c}\text { Resin cement } \\
\text { (immediate) }\end{array}$} & Mean & .968 & .895 & .649 & .485 & .495 \\
\hline & SD & 0.1 & .019 & .016 & .012 & .012 \\
\hline \multirow{2}{*}{$\begin{array}{c}\text { Resin cement } \\
\text { ( } 24 \text { hours) }\end{array}$} & Mean & 0.991 & 0.998 & 0.876 & 0.876 & 0.876 \\
\hline & SD & 0.002 & 0.008 & 0.009 & 0.007 & 0.008 \\
\hline \multicolumn{2}{|c|}{$\mathrm{t}$} & 0.514 & 11.17 & 27.65 & 62.93 & 59.08 \\
\hline \multicolumn{2}{|c|}{$\mathrm{P}$} & $0.62 \mathrm{~ns}$ & $0.00 *$ & $0.00 *$ & $0.00 *$ & $0.00 *$ \\
\hline
\end{tabular}




\section{D- Interaction of both variables}

Two ways ANOVA test revealed that the depth variable resulted in a statistically significant difference $(p=0.00)$, while the material variable caused a non-significant difference $(p=0.087)$. Interaction of both variables showed a statistically significant difference $(\mathrm{P}=0.00)$, (Table 6)

TABLE (6) Two ways ANOVA test

\begin{tabular}{|l|r|r|r|r|r|}
\hline Source & $\begin{array}{c}\text { Type III Sum } \\
\text { of Squares }\end{array}$ & df & $\begin{array}{c}\text { Mean } \\
\text { Square }\end{array}$ & \multicolumn{1}{|c|}{ F } & Sig. \\
\hline Depth & 3.820 & 4 & .955 & 2400.410 & $.000 *$ \\
\hline Material & .001 & 1 & .001 & 3.076 & $.087 \mathrm{~ns}$ \\
\hline $\begin{array}{l}\text { Depth * } \\
\text { Material }\end{array}$ & .801 & 4 & .200 & 503.177 & $.000 *$ \\
\hline
\end{tabular}

Significance level $P<0.05$, * significant, $n$ s=non-significant

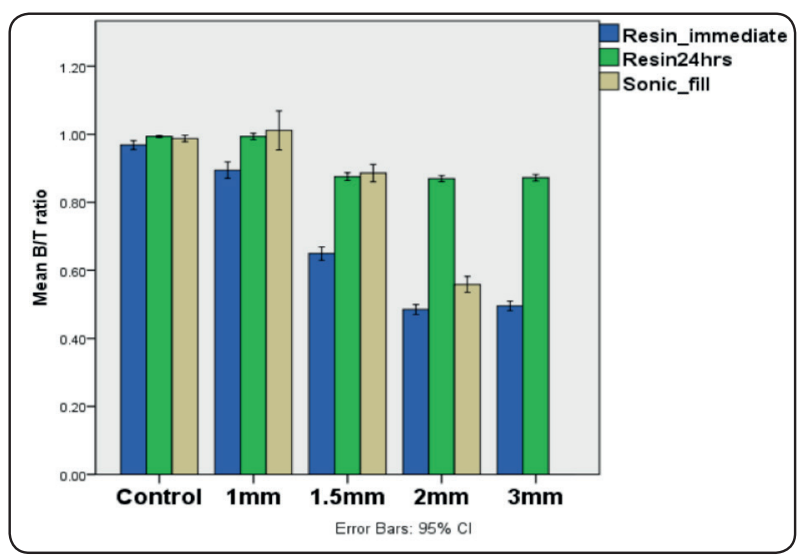

Fig. (1) Column chart showing mean $\mathrm{B} / \mathrm{T}$ ratio in different groups

\section{DISCUSSION}

Clinical studies describe the high performance of bonded indirect esthetic restorations regarding esthetics and good survival rate, not only to restore anterior teeth, but also for extensive posterior restorations. For both indications, the clinical success of indirect tooth colored restoration greatly depends on the type of resin cement used. Traditionally, a dual-cure resin cement is preferred for the placement of indirect restorations, to ensure effective polymerization even through thick and/ or opaque restorations ${ }^{(2,6,8,36)}$. The current study evaluate the depth of cure of sonic bulk fill light cured resin composite material (SonicFill2, Kerr) for cementation of CAD/CAM composite block versus the traditionally used dual cured resin cement (Dual-link universal, Bisco) by assessing microhardness at the top and bottom and calculating bottom/top ratio.

The dual-cure chemistry apparently combines the assurance of 'dark' chemical curing. However the wholly light cured resin composites include improved handling features as a single paste that require no mixing, on command setting and hence better control of the working time, faster setting, easy removal of excess additionally improved color stability as light curable resin composites usually contain more fillers than dual cure resin cements, hence higher intrinsic mechanical and physical properties ${ }^{(25-31)}$. In addition the sonic activation of the regular flow composite enhances the flowing properties of the material to be used for cementation. Even with these advantages, very few works investigated the use of purely lightcurable composites to lute indirect restorations ${ }^{(36)}$. In the present study, the depth of cure of SonicFill2 which is a light cured bulk fill resin composite was evaluated as a new trend in cementation protocol for indirect esthetic restorations in comparison to Dual-link universal as a traditional dual cured resin cement. A CAD/CAM composite block (Grandio) was used with different thicknesses to determine the optimal degree of conversion and depth of cure of both resin materials used for cementation. Microhardness assessment was performed at the top and bottom of resin materials after curing degree of conversion was determined by calculating the bottom/top ratio that was assigned to be $80 \%$ of the maximum material microhardness. Since 
the depth of cure is an important tool to estimate the properties of resin composite restorations ${ }^{(34)}$, different methods are available to assess the depth of cure of resin composite restoration. The surface hardness measurements, whether Vickers or Knoop indenters, is one of the most widely used method for indirect determination of the depth of cure of resin composites. A good correlation was found between increasing hardness and increasing depth of cure ${ }^{(35)}$. Thus, in this study the depth of cure was assessed using Digital Display Vickers Microhardness Tester, since it is easy to apply and the data obtained are reliable ${ }^{(34)}$. Moreover, in this study Vickers microhardness number (VHN) was determined on the top and the bottom surfaces for each specimen since the light intensity is attenuated when passing through the composite due to light scattering effect of filler/matrix refractive index mismatch ${ }^{(35)}$. As a consequence, the bottom surface is more critically affected by the light intensity, so it is considered as a good surface to estimate the effectiveness of cure of composite ${ }^{(34)}$. Thus, assessment of bottom/ top surface hardness percent is a valuable indicator of the thoroughness of cure of a sample. Ideally, the degree of polymerization of the composite should be the same throughout its depth and the hardness percentage should be very close or equal to hundred. However, there is a general consensus in the literature that a value of $80 \%$ bottom/top percentage is considered the minimally acceptable value for light cured resin-composites ${ }^{(33-35)}$.

The results of the present study were that, immediately, in control, a higher mean value was recorded in Sonicfill2 group, with a statistically significant difference $(\mathrm{p}=0.011)$. In $1 \mathrm{~mm}, 1.5 \mathrm{~mm}$, $2 \mathrm{~mm}$ thickness of indirect esthetic restoration, a higher mean value was recorded in SonicFill 2 group, with a statistically significant difference $(\mathrm{p}=0.003$, $\mathrm{p}=0.00, \mathrm{p}=0.00$ respectively). In $3 \mathrm{~mm}$ resin cement recorded a mean value of $0.495 \pm 0.012$ (Table 1 , Fig.1). However, after 24 hours, in control, a higher mean value was recorded in resin cement group, with no statistically significant difference $(\mathrm{p}=0.44)$. In $1 \mathrm{~mm}, 1.5 \mathrm{~mm}$, a higher mean value was recorded in SonicFill 2 group, with no statistically significant difference ( $\mathrm{p}=0.55, \mathrm{p}=0.356$ respectively). In $2 \mathrm{~mm}$, resin cement recorded a significantly higher mean value $(\mathrm{p}=0.00)$. In $3 \mathrm{~mm}$, resin cement recorded a mean value of $0.876 \pm 0.008$ (Table 2, Fig.1).

These results denoted that the resin composite material presented by SonicFill 2 has a higher physical and mechanical properties in comparison with dual cures resin cements with adequate polymerization when used for cementation of indirect restoration with average thickness of $1.5 \mathrm{~mm}$. Unfortunately, this result couldn't be maintained at $2 \mathrm{~mm}$ thickness as there is significant decrease in degree of conversion and depth of cure. Moreover, at $3 \mathrm{~mm}$ thickness no curing was obtained and this might be attributed to several factors as the light transmittance through an esthetic indirect restoration is significantly affected by the type of material. Veneers are commonly fabricated with feldspathic porcelain, that demonstrate relatively high translucency, however, more opaque materials exist, especially those fabricated using $\mathrm{CAD} /$ CAM processes, including resin-based composites, particle reinforced ceramic composites (e.g. lithium disilicates and leucite-based ceramics) and polycrystalline ceramics (e.g. alumina and zirconia). Therefore, if light transmission is limited by the opacity of the indirect material, for effective polymerization a higher irradiance curing devices are required together with increasing curing times ${ }^{(8-10,36)}$. Definitely, low transmittance is expected through thick indirect material layers, which explains the relatively long irradiation times that were used when luting with light-activated (non-dual cure) resin composites (from $40 \mathrm{~s}$ [10] to several cycles of $90 \mathrm{~s}) .{ }^{(8-10,36)}$

On the other hand, in the present study, although the results of dual cure resin cement was less than that of sonic fill2 at immediate measurement with idirest esthetic restoration of average thickness of 
$1.5 \mathrm{~mm}$ but it show adequate polymerization after 24 hours in all restoration thicknesses as inlays, onlays and endocrowns. This may be attributed to the" dark" autopolymerization process that occurs after 24 hours. A previous study has reported a threefold decrease in microhardness of dual-cure resin cement when light cured through thick $(4 \mathrm{~mm})$, compared with thinner thinner ( $2 \mathrm{~mm}$ or less), or no use of indirect ceramic filters . A similar observation was made when measuring the degree of conversion of a dual-cure resin cement, with a two- to fourfold decrease of conversion through opaque $2 \mathrm{~mm}$ ceramic filters $^{(36)}$. The autopolymerization step in a dual-cured system seems therefore was beneficial to ensure optimal polymerization of luting indirect esthetic restoration. Hence, undercuring of dualcure materials or wholly light cured materials beneath thick or opaque indirect restorations remains a risk, which is potentially worsened with systems that use light-curable chemistries alone. Effective polymerization of the latter is indeed necessary to ensure optimal physico-mechanical properties and color stability, thereby reducing the risk of interfacial failure.

\section{CONCLUSIONS}

Under the limitation of the current study it could be concluded that Sonic bulk fill light cured resin composite as new trend in cementation procedure can be efficiently cured through CAD/CAM composite blocks with thin thickness not more than $1.5 \mathrm{~mm}$. Indeed, dual curable resin cement remains convenient for cementation of thicker indirect esthetic restoration such as inlay, onlay and endocrown.

\section{Further investigation}

Further investigation are required to evaluate the effect of different light intensities and different irradiation time in addition to the effect of different CAD/CAM blocks materials on the depth of cure of light cured resin composite as new trend in cementation of indirect esthetic restoration.

\section{REFERENCES}

1. Fasbinder DJ. Chairside CAD/CAM: an overview of restorative material options. Compend Contin Educ Dent 2012;33(50):52-8.

2. Fasbinder DJ, Dennison JB, Heys D. Clinical evaluation of CAD/CAM-generated composite inlays: ten-year report. J Dent Res 2011;90(special issue A). Abstr. No. 0379.

3. Sorensen JA. CAD/CAM: converging technologies, improved milling materials expand dental applications. Compend Contin Educ Dent 2012;33:538-9.

4. Van Meerbeek B, Inokoshi S, Willems G, Noack MJ, Braem M, Lambrechts $P$, et al. Marginal adaptation of four tooth-coloured inlay systems in vivo. J Dent 1992;20: 18-26.

5. Hori S, Minami H, Minesaki Y, Matsumura H, Tanaka T. Effect of hydrofluoric acid etching on shear bond strength of an indirect resin composite to an adhesive cement. Dent Mater J 2008;27:515-22.

6. Gu X, Kern M. Marginal discrepancies and leakage of all-ceramic crowns: influence of luting agents and aging conditions. Int J Prosthodont 2003;16:109-16.

7. Lührs AK, Pongprueksa P, De Munck J, Geurtsen W, Van Meerbeek B2.Curing mode affects bond strength of adhesively luted composite CAD/CAM restorations to dentin. Dent Mater. 2014 Mar;30(3):281-91.

8. Lise DP, Van Ende A, De Munck J, Yoshihara K, Nagaoka N, Cardoso Vieira LC, Van Meerbeek B. Light irradiance through novel CAD-CAM block materials and degree of conversion of composite cements. Dent Mater. 2018 Feb;34(2):296-305.

9. Calheiros FC, Kawano Y, Stansbury JW, Braga RR. Influence of radiant exposure on contraction stress, degree of conversion and mechanical properties of resin composites. Dent Mater 2006;22:799-803.

10. Souza GDE, Braga RR, Cesar PF, Lopes GC. Correlation between clinical performance and degree of conversion of resin cements: a literature review. J Appl Oral Sci 2015;23:358-68.

11. De Munck J, Vargas M, Van Landuyt K, Hikita K, Lambrechts P, Van Meerbeek B. Bonding of an autoadhesive luting material to enamel and dentin. Dent Mater 2004;20:963-71.

12. Sarr M, Mine A, De Munck J, Cardoso MV, Kane AW, Vreven $\mathrm{J}$, et al. Immediate bonding effectiveness of contemporary composite cements to dentin. Clin Oral Investig 2010;14:569-77. 
13. Arrais CA, Giannini M, Rueggeberg FA, Pashley DH. Microtensile bond strength of dual-polymerizing cementing systems to dentin using different polymerizing modes. J Prosthet Dent 2007;97:99-106.

14. Faria-e-Silva AL, Fabião MM, Arias VG, Martins LR. Activation mode effects on the shear bond strength of dualcured resin cements. Oper Dent 2010;35:515-21.

15. Garcia RN, Reis AF, Giannini M. Effect of activation mode of dual-cured resin cements and low-viscosity composite liners on bond strength to dentin. J Dent 2007;35: 564-9.

16. Tay FR, Pashley DH, Yiu CK, Sanares AM, Wei SH. Factors contributing to the incompatibility between simplified-step adhesives and chemically-cured or dual-cured composites. Part I. Single-step self-etching adhesive. J Adhes Dent 2003;5:27-40.

17. Rathke A, Hokenmaier G, Muche R, Haller B. Effectiveness of the bond established between ceramic inlays and dentin using different luting protocols. J Adhes Dent 2012;14: 147-54.

18. Vieno S, Madini L, Barabanti N, Alessandri I, Gagliani M, Cerutti A. Indirect resin composite restorations: evaluation of polymerization of luting agents by means of micro-Raman spectrophotometry. Minerva Stomatol 2009;58:1-8.

19. Price RB, Whalen JM, Price TB, Felix CM, Fahey J. The effect of specimen temperature on the polymerization of a resin-composite. Dent Mater 2011;27:983-9.

20. Franc, a FÁ, Oliveira Md, Rodrigues JA, Arrais CA. Preheated dual-cured resin cements: analysis of the degree of conversion and ultimate tensile strength. Braz Oral Res 2011;25:174-9.

21. Faria-e-Silva AL, Casselli DS, Lima GS, Ogliari FA, Piva E, Martins LR. Kinetics of conversion of two dual-cured adhesive systems. J Endod 2008;34:1115-8.

22. Arrais CA, Rueggeberg FA, Waller JL, de Goes MF, Giannini M. Effect of curing mode on the polymerization characteristics of dual-cured resin cement systems. J Dent 2008;36:418-26.

23. Ilie N, Simon A. Effect of curing mode on the micro-mechanical properties of dual-cured self-adhesive resin cements. Clin Oral Investig 2012;16:505-12.

24. Coelho Santos MJ, Navarro MF, Tam L, McComb D. The effect of dentin adhesive and cure mode on film thickness and microtensile bond strength to dentin in indirect restorations. Oper Dent 2005;30:50-7.

25. Schulte AG, Vöckler A, Reinhardt R. Longevity of ceramic inlays and onlays luted with a solely light-curing composite resin. J Dent 2005;33:433-42.
26. Barabanti N, Preti A, Vano M, Derchi G, Mangani F, Cerutti A. Indirect composite restorations luted with two different procedures: a ten years follow up clinical trial. J Clin Exp Dent 2015;7:e54-9.

27. D'Arcangelo C, De Angelis F, Vadini M, D'Amario M. Clinical evaluation on porcelain laminate veneers bonded with light-cured composite: results up to 7 years. Clin Oral Investig 2012;16:1071-9.

28. D'Arcangelo C, Zarow M, De Angelis F, Vadini M, Paolantonio M, Giannoni M, et al. Five-year retrospective clinical study of indirect composite restorations luted with a light-cured composite in posterior teeth. Clin Oral Investig 2014;18:615-24.

29. Coelho Santos MJ, Navarro MF, Tam L, McComb D. The effect of dentin adhesive and cure mode on film thickness and microtensile bond strength to dentin in indirect restorations. Oper Dent 2005;30:50-7.

30. Meng X, Yoshida K, Atsuta M. Influence of ceramic thickness on mechanical properties and polymer structure of dual-cured resin luting agents. Dent Mater 2008;24:594-9.

31. C Poggio, M Lombardini, S Gaviati, and M Chiesa: Evaluation of Vickers hardness and depth of cure of six composite resins photo-activated with different polymerization modes. J Conserv Dent. 2012 Jul-Sep; 15(3): 237-241.

32. Leprince, J.G., Leveque, P., Nysten, B., Gallez, B., Devaux, J. and Leloup, G.,. 'New insight into the "depth of cure" ofdimethacrylate-based dental composites'. Dental Materials, (2012) 28 (5):512-520.

33. Abed, Y.A., Sabry, H.A. and Alrobeigy, N.A., 'Degree of conversion and surface hardness of bulk-fill composite versus incremental-fill composite'. Tanta Dental Journal, (2015). 12 (2):71-80.

34. Poggio, C., Lombardini, M., Gaviati, S. and Chiesa, M., 'Evaluation of Vickers hardness and depth of cure of six composite resins photo-activated with different polymerization modes'. Journal of Conservative Dentistry, (2012). 15 (3):237.

35. Alshali, R.Z., Salim, N.A., Satterthwaite, J.D. and Silikas, N., 'Post-irradiation hardness development, chemical softening, and thermal stability of bulk-fill and conventional resin-composites'. Journal of Dentistry, (2015). 43 (2):209-218.

36. Hardy C.M.F., Bebelmanc S., Leloupa G., Hadise M.A., Palin W.M., Leprince J.G.:Investigating the limits of resin-based luting composite photopolymerization through various thicknesses of indirect restorative materials dental materials 34 (2018) 1278-1288. 